\title{
The New Systemic Re-use For Old Italian ANAS Houses
}

\section{Francesca Andrulli Chiara Bonaiti* Alessia Silvetti ${ }^{\star \star}$}

\section{Abstract}

The paper is about conservation and new use of four ANAS Company houses (along the last 19-early 20 centuries roads) located on Lake Como. The conservation project is on the roadmen's houses for workers of "ANAS", the Italian Company for building and maintenance of Italian roads.

These houses are architectural buildings that characterize the Italian intercountry streets. They have been built along Italy every $50 \mathrm{~km}$, with the same typology and dark red colour. Currently they are abandoned. In these last years, ANAS Company has fired several workers and now the houses aren't in use.

The project aims to conserve and maintain the existing materials and structures and reuse the buildings with a systemic project about accommodating functions (food and drinks).

Not just to a systemic use and to conservative interventions, during planning we make particular attention to the link among the four roadmen's houses chosen as study cases. We want to create a slow tourism path by increasing existing cycle and pedestrian mobility.
Keywords: Roadman's house, minimum intervention, compatibility, authenticity.

*Tutor at the School of Building Architecture and Engineering, Polytechnic of Milan, Italy. E-mail: francesca.andrulli@mail.polimi.it Orcid ID: http://orcid.org/0000-0002-71534603

**Tutor at the School of Building Architecture and Engineering, Polytechnic of Milan, Italy. E-mail: chiara.bonaiti@mail.polimi.it Orcid ID: http://orcid.org/0000-0002-79526114

***Adjunct professor at the School of Building Architecture and Engineering, Polytechnic of Milan, Italy.

E-mail: alessia.silvetti@polimi.it

Orcid ID: http://orcid.org/0000-0002-42836274 


\section{INTRODUCTION}

The ANAS house, with a typical Pompeian red colour on its facades, was created to provide accommodation for workers who had to take care of maintaining a specific section of Italian roads. There are 1.244 houses in Italy, half of which are used as operational sites, for working employees, warehouses or other functions. Over the years many of these structures have lost their function becoming abandoned places and degraded points in the city. The solution to revitalize these structures was found with the redevelopment project proposed in agreement with the Ministry for Cultural Assets and Activities (Mibact), the Ministry of Infrastructures and Transport (Mit) and the State-owned Agency. The goal is to redevelop these typical Italian places through the characteristics which make them unique: colour, architecture, strategic position and panoramic view.

In the map below (ANAS, 2016), the roadmen's houses are symbolically represented on the national territory. It is easy to note that the buildings were all born along the main national distribution routes, like 'Via del Nord' and 'Valle d'Ampezzo', 'Via Francigena' and 'Via Appia'. The density of construction is higher in the upper part of Italy, while houses are less widespread towards the Mediterranean Sea, according with the concentration of the Italian roads' network.

Figure 1. National distribution of roadmen's houses. (ANAS, 2016).

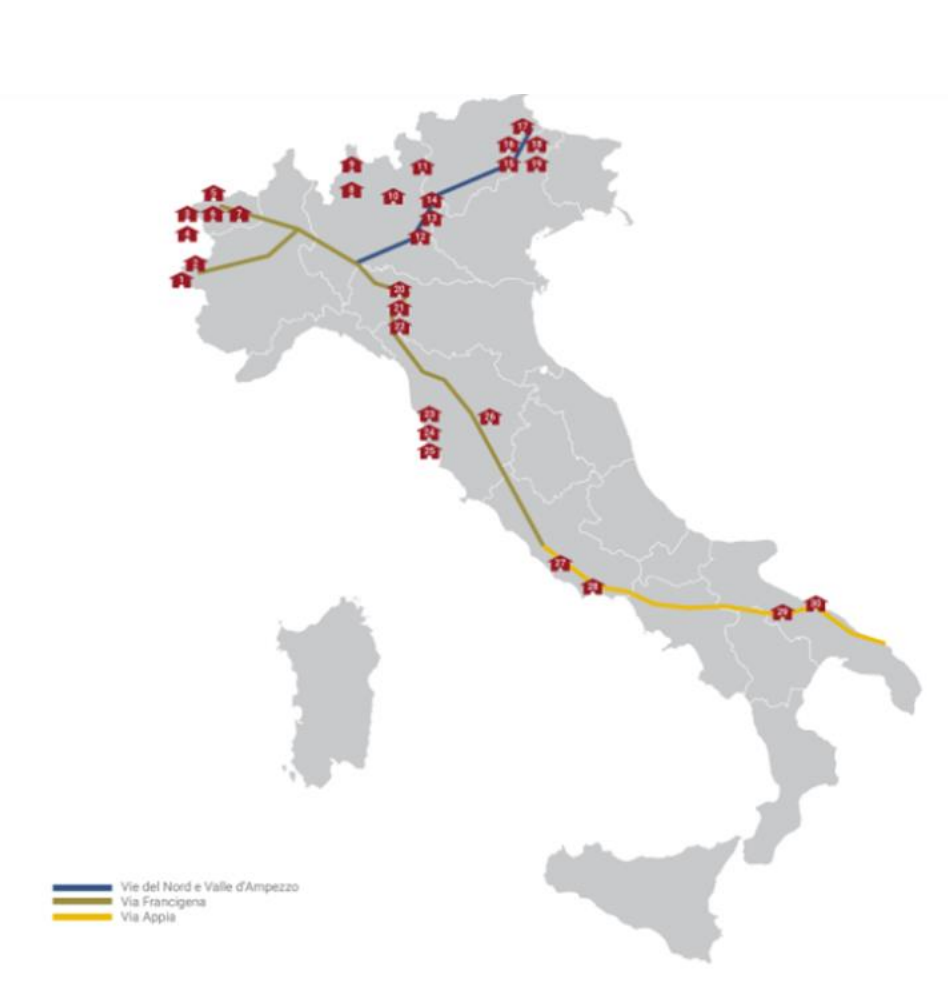

On the Official Gazette (Gazzetta Ufficiale, 2016) a call for proposals has been published. Its aim is recover the existing building heritage and create a modern reference point to support drivers, offering high-quality hospitality and catering. The goal is improving the territory in which these houses are located. 
The spirit of our design is "Travel, stop, rediscover" exactly as proposed by the initiative (Case Cantoniere, 2016).
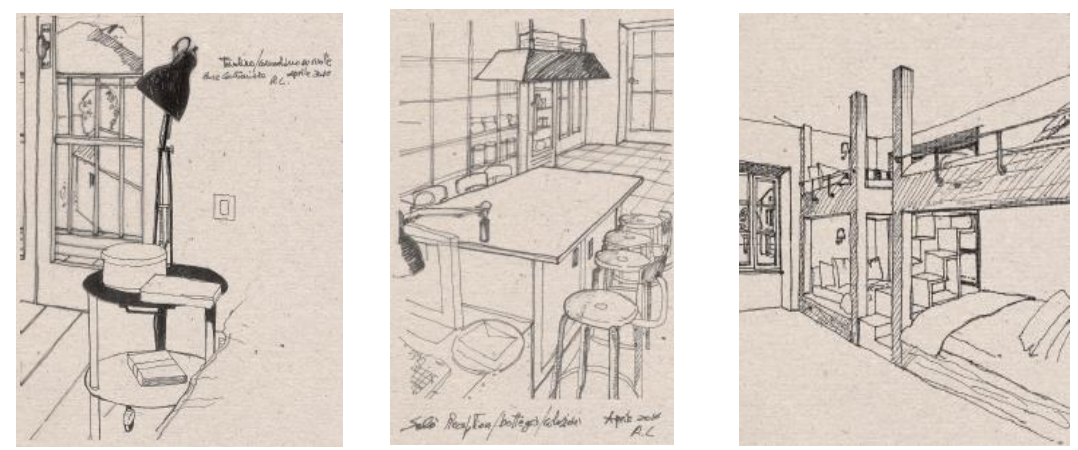

The pilot scheme concerns the assignment and redevelopment of the first 30 roadmen's houses selected, according to the greatest potential, within the heritage of the government property.

This paper deals with the project of four houses located in Lecco along the route that runs along the well-known Lake Como: Airuno, Garlate, Abbadia Lariana and Dervio's houses. We start from a large-scale concept in which we determine the project idea, in order to create a real network that connects the four buildings.
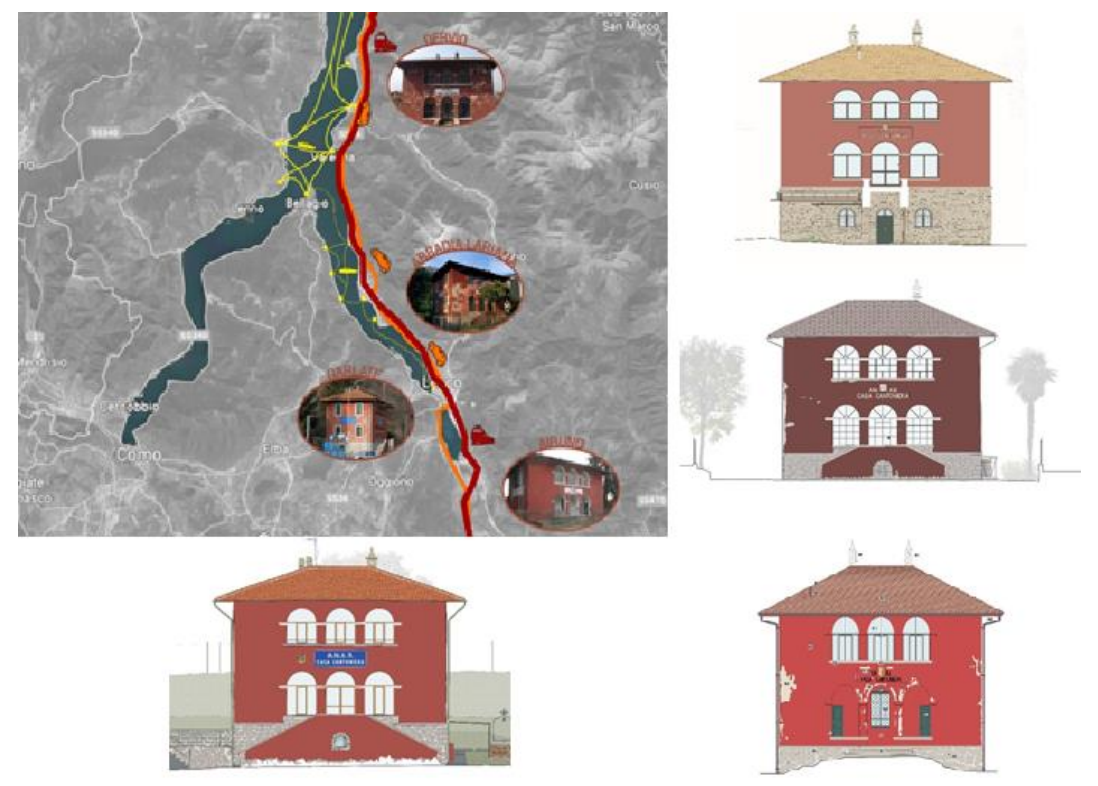

Tourism, culture, hospitality and catering (food and beverage): these are the services offered to customers of the roadmen's houses. (Case Cantoniere, 2016).

Starting from a proposed use at a systemic level, we move to the project of the specific building giving all necessary details: from a geometric survey we start an analysis of the materials typical of the building, then we make a degradation survey in order to identify the best intervention to restore materials by strengthening them without modifying their original appearance.
Figure.2. Drawings from www.casecanto niere.it

Figure 3. Main views of the four ANAS houses: Garlate, Abbadia Lariana, Airuno and Dervio. Lombardia, Italy.

[Restoration class at the School of Building Architecture and Engineering at Polytechnic of Milan in Lecco, 2017] 
Figure 4. Architectural features of ANAS houses.
The design process described in this paper takes up an academic path of analysis and study carried out during the restoration course at the Polytechnic of Milan in Lecco.

The project proposed wants to underline as much as possible the architectural features typical of ANAS houses:

- Pompean red tint on facade;

- Three entrance arches, often reproduced on the upper floor;

- External doors in wood with green oil paint;

- Roof tiles;

- Garden and outdoor green furniture.

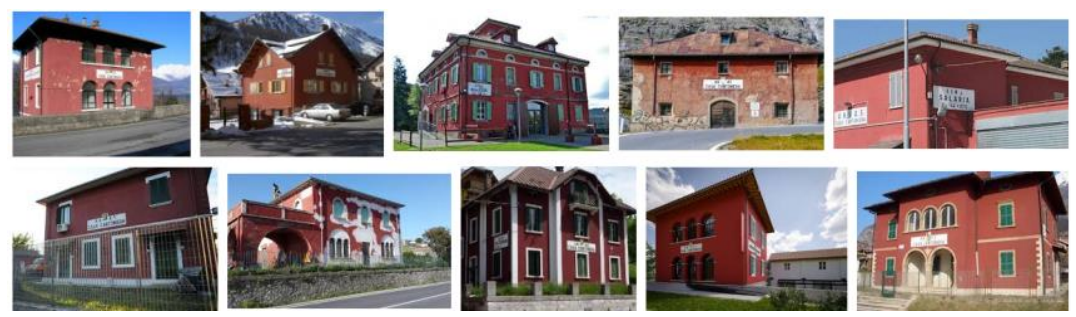

The conservative project of restauration, designed for each of the four houses, determines a precise solution in which the objective is to fully underline the peculiar characteristics of the building. We want to show each house in the best way, but accurately, in respect to what has been, we always keep in mind the essential principles of a good restoration: reversibility, minimum intervention, recognizability, compatibility and respect of the existing object. All of these rules must be combined with a touch of innovation through the principle of sustainability.

'The good restoration can be called a drowning of itself in the face of the past. The more the artist today bows, kneels, gets married against the monument, the better he performs his own.' - (Boito, 1880).

\section{PLANNING AIMS}

These are the goals of the redevelopment and re-use of ANAS houses:

- Preserve the buildings with their specific features (red colour);

- Realize a systematic reuse with a unique end use;

- Enhance the connection system among the four buildings with an application of slow tourism;

- Develop local traditional products to create an attractive hub for residents and tourists.

\section{TYPOLOGY OF THE ROADMAN'S HOUSE}

The houses are located in different geographical areas within the Italian territory and have different features depending on the climate, the altitude and the local building techniques. In our 
specific study case houses are located in the north of Italy and have different characteristics compared to houses built in other Italian areas. The structure of the architectural asset has a very simple volume consisting of a single building of three floors above ground and a loggia with three arches on the main facade that characterizes the building. The wall, made by local stone of Moltrasio in the basement and bricks in the upper floors, is covered with cement mortar and Pompeian red tint as finishing. The place on which they are built is generally lakefront. This is an element that gives a particular environmental value to the houses.
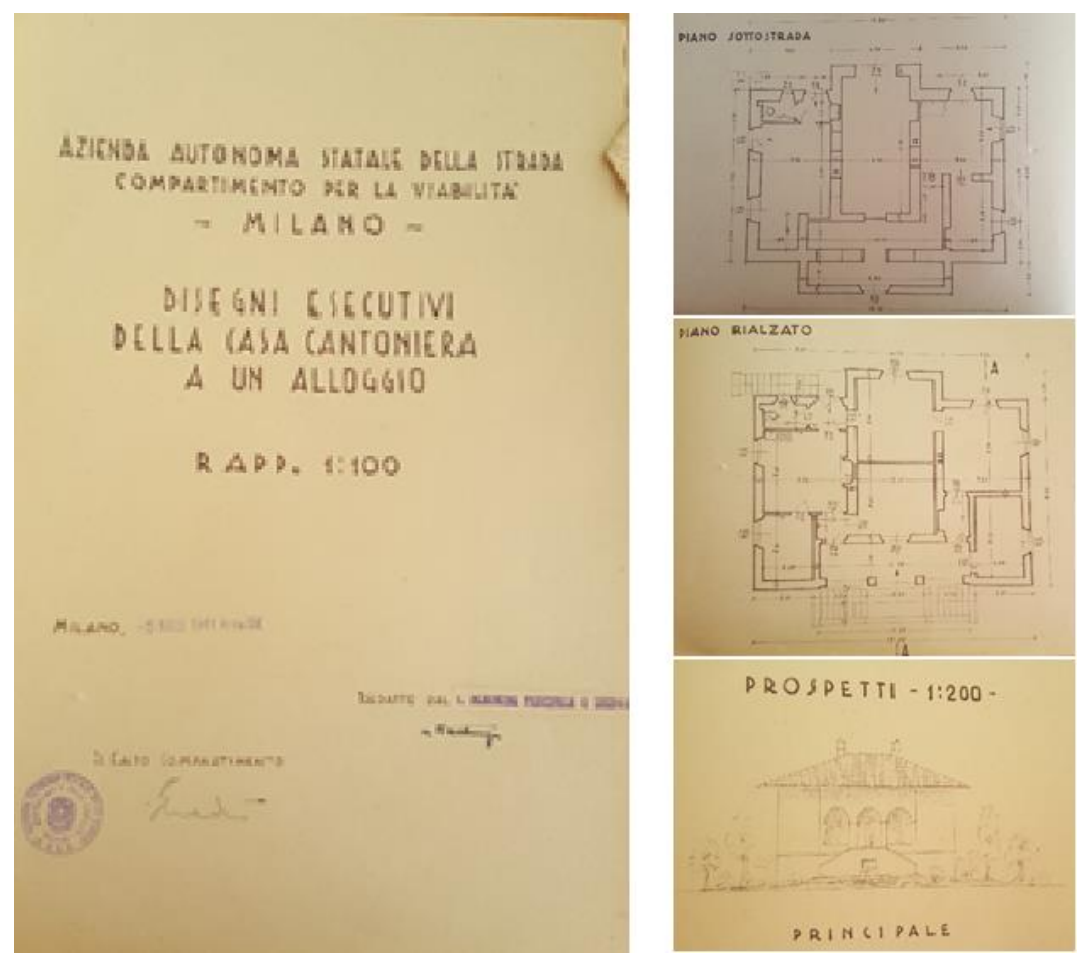

\section{ANAS HOUSES: PLANNING OF CONSERVATION AND SYSTEMATIC REUSE}

The actions identified in the proposed systematic re-use of the four ANAS houses are defined giving a key role to the criteria of conservative restoration, such as minimum intervention aimed at keeping untouched the authenticity of the buildings on which we are going to make a restoration project.

The conservative interventions proposed to give a new life to the buildings want to keep untouched the original view that identifies the traditional image of the roadman's house situated on the lakefront road. The houses 'with the red-façade', nowadays in a state of abandon, are identified with traditional materials that are fixed in the common idea.

We don't have to change or damage the original materials during the intervention of reuse. This goal comes from the wish to keep alive the authenticity of existing edifices.
Figure 5. Drawings found in ANAS archive, Rome. 
The interventions are conservative, reversible, distinguishable and compatible with the existing structure. With the new project we want to preserve existing building's integrity according with the principle of minimum intervention.

'Reversible changes should be considered temporary. Non-reversible change should only be used as a last resort and should not prevent future conservation action' - (ICMOS, 1979)

Figure 6. The typical 'red facade': Roadman's house in Dervio.

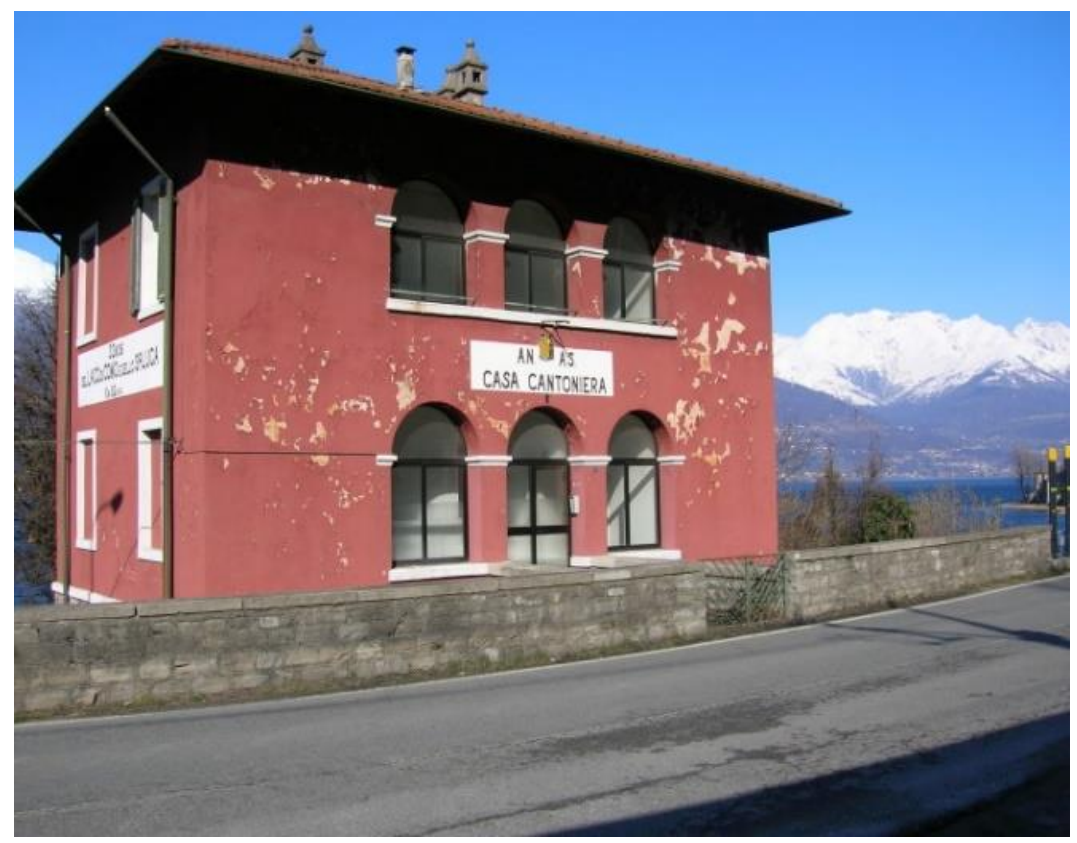

The methodology based on research and analysis is aimed at identifying a new use respecting the traditional image of the roadman's house and the surrounding landscape. We propose a suitable use after a careful study of the four ANAS houses and of the countries where they are located in. The reuse of the buildings wants to create an attractive pole for local population and tourists.

The project describes the reuse of the four houses located along Lake Lecco, with the purpose of creating a slow tourism way that increases cycle-pedestrian mobility (Grandtour, 2016). The buildings are situated along an existing lakefront cycle path that in some parts is under construction (Marcarini, 2005). Slow tourism wants to be employed to ensure a sustainable accessibility to the reused edifices. The study of slow mobility is part of the systemic project that aspire to connect the different roadmen's houses with a single design's concept in order to generate a masterplan that fixes a solid link among the different buildings situated along the same road (Guidelines,2009). 


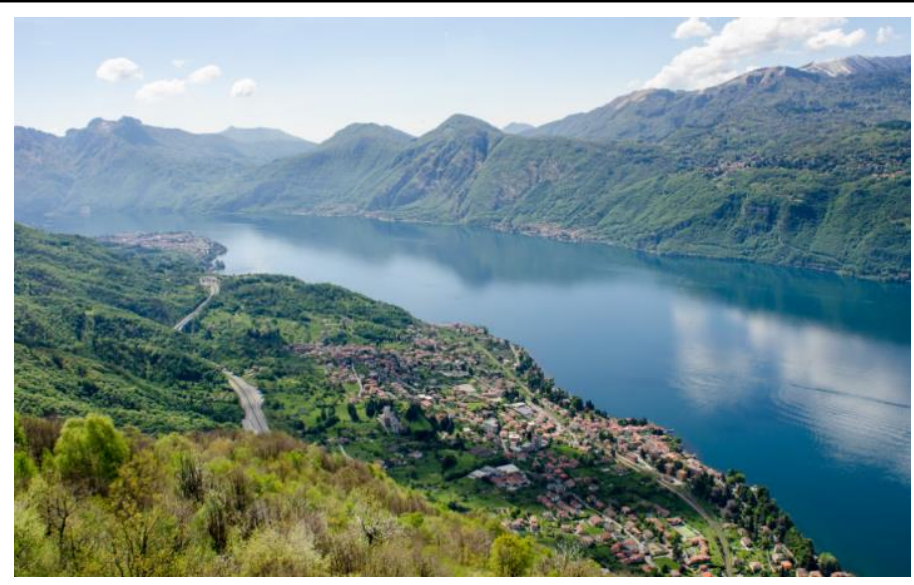

The countries that host the buildings described in this paper have very different qualities: Abbadia Lariana and Dervio have a welldeveloped tourist vocation in their territory thanks to their strategic position and panoramic view on the lake; Garlate and Airuno, further from lake, are in a less privileged position. We choose to put in a tourist-accommodating use to revitalize the roadmen's houses according with the requests of the competition announcement. The indoor and outdoor spaces are studied using the hosting theme in an original way. After the phase of knowledge characterized by a careful analysis of the territory and the possible services needed in the places around the four houses, we propose structures that offer refreshment areas for tourists and local people. The catering function is designed to offer the opportunity to taste local products that comes from the territory around houses. The idea is to propose different dishes for each ANAS house, linked to the background in which they are situated. The food and beverage's tasting itinerary of typical local dishes begins with the Airuno's house where you can taste appetizers linked to culinary tradition of Lake Lecco. After Airuno, we can reach the first courses offered in Garlate's house. The main courses are available in the houses of Abbadia Lariana and Dervio, where, in order, meat and fish dishes are proposed.

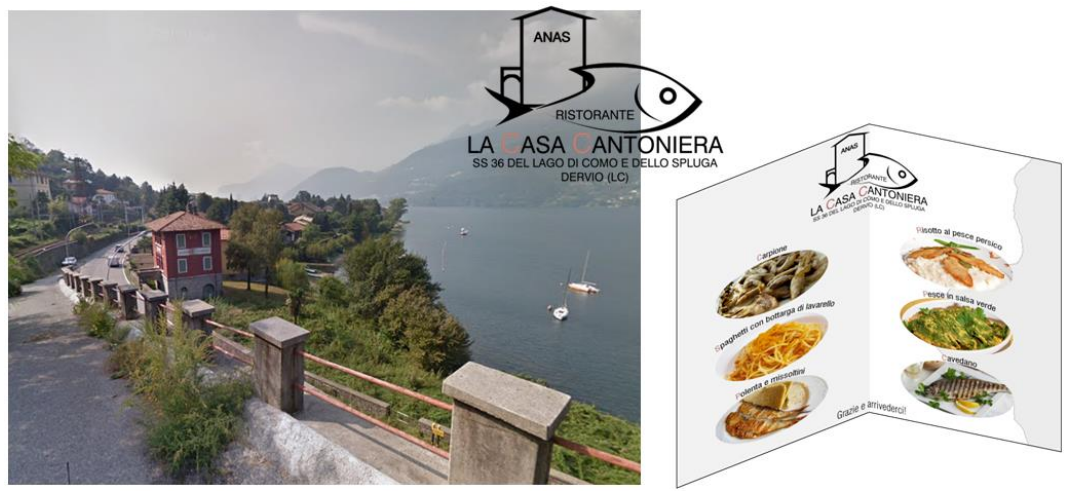

The central theme that connects the four houses is wine, a traditional product of the territory, which is offered in each new receptive hub. The suggestion is well strengthened because some countries of Lecco and Como, including the four countries studied, belong to the 'Terre Lariane consortium' (Terre Lariane, 2016), which produces many certified DOC and IGP wines. The project is
Figure 7. The lakefront road: 'Viandante path' (Marcarini, 2005).

Figure 8. Roadman's house in Dervio: fish dishes.

[Restoration class at the School of Building Architecture and Engineering at Polytechnic of Milan in Lecco, 2017] 
Figure 9. Design concept: 'Tasting houses' (in Italian 'Le case del gusto'] [Restoration class at the School of Building Architecture and Engineering at Polytechnic of Milan in Lecco, 2017] called 'Tasting Houses' to highlight the activities chosen during the planning. The receptive theme is applied in order to revitalize enogastronomic traditions in a vision of touristic promotion and implementation of opportunities offered to citizens. We want to create a food\&drink path organized in stages that connects the different houses creating a unique linking project.
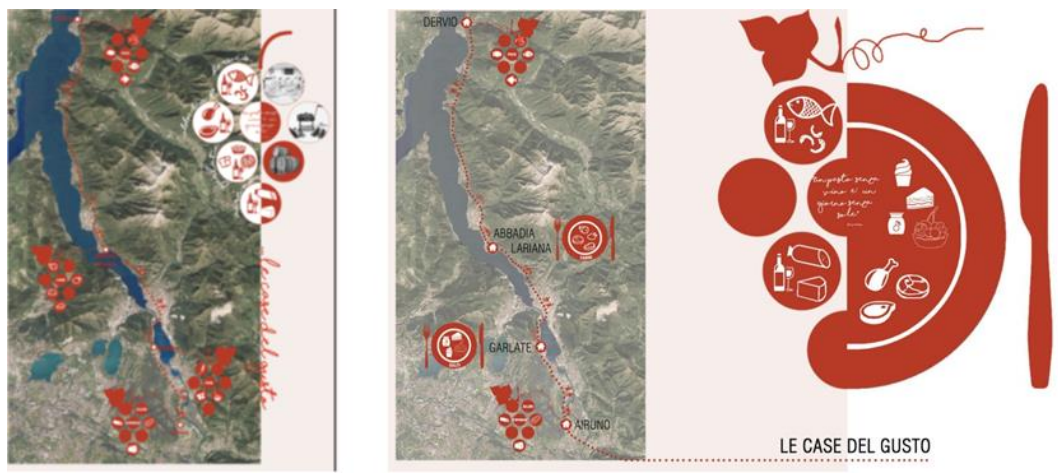

The connection among the buildings is also underlined by the improvement and valorisation of the existing cycle path along the lakefront. In each building we plan to install a fixing and parking place for bicycles for users who follow the slow tourism path. The roadmen's houses located in different countries have specific aspects that are repeated. All buildings have a front situated on a high traffic road and a lakefront facade, more or less close to the coast. Behind the buildings there is a garden where we propose to have social vegetable gardens which can be used by local population and tourists. The gardens are designed to allow users to work on some local crops used to prepare food served during tastings in the 'Tasting houses'. In this way we use the project theme to revitalize countries by showing traditions consolidated in the territory. 

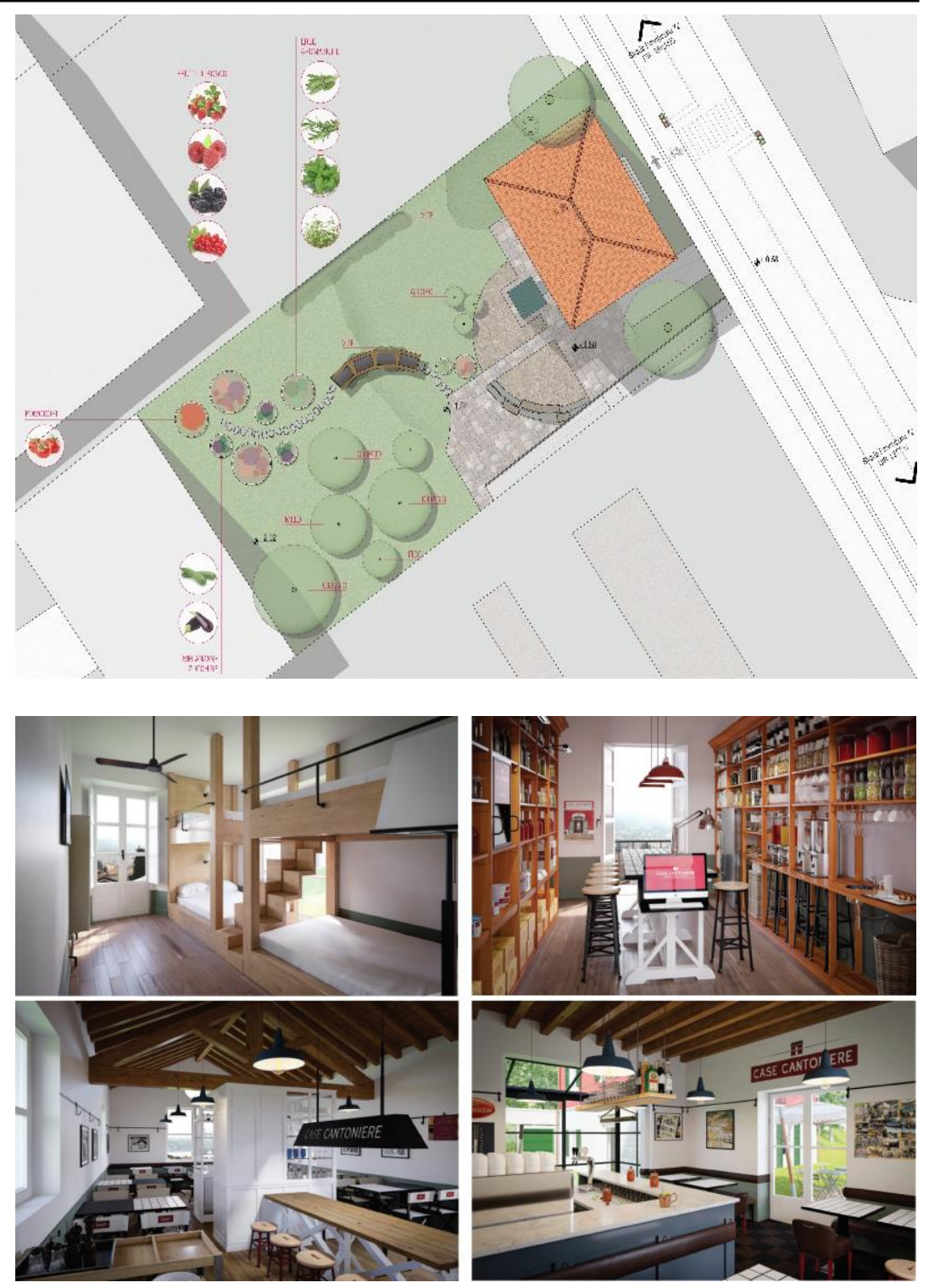

The conservative interventions of restoration and the distribution of indoor spaces are studied in detail for each of the four buildings described in this paper. For example, in the study of the house of Abbadia Lariana we turn into a strengthness the exfoliation of the main part of plaster on roadfront façade: this aspect could superficially appear a point of weakness. In the part where plaster has lost its distinctive red colour becoming grey, we create a mural that recalls the characteristic product offered inside the building: grilled meat. In this way we confirm the respect of minimum intervention and the recognisability of the existing building that are essential principles in restoration (ICOMOS, 2003).
Figure 10. Example of masterplan: roadman's house in Airuno.

[Restoration class at the School of Building Architecture and Engineering at Polytechnic of Milan in Lecco, 2017]

Figure 11. Example of projects. (ANAS, 2016). 
Figure 12. Roadman's house in Abbadia Lariana: 'before and after reuse intervention'.

[Restoration class at the School of Building Architecture and Engineering at Polytechnic of Milan in Lecco, 2017]
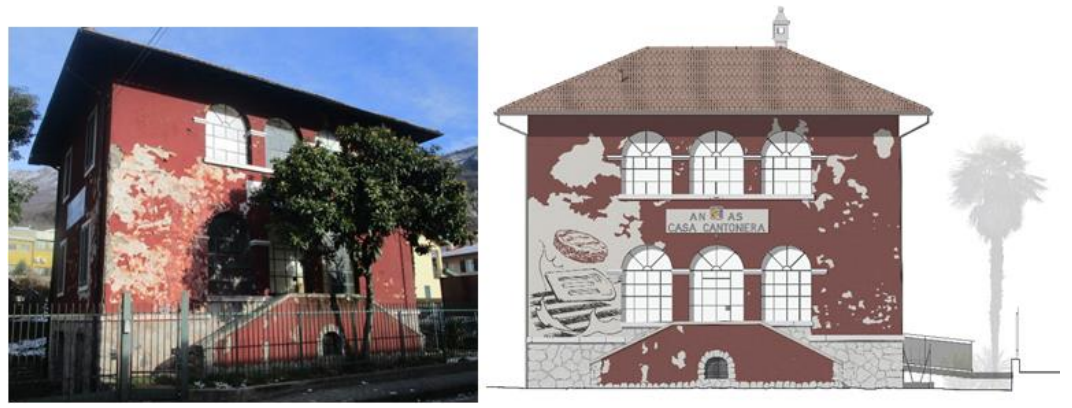

\section{CONCLUSIONS}

Over the years, the roadmen's houses have become recognizable architectures along the route. They are symbols of an era in which road mobility became a key resource for the connections among cities and for the economic development of Italy. Preserving buildings in their typology and materiality is essential to maintain the identity of a historical period of Italian culture. The conservation and transmission to future generations of ANAS houses and their reuse in respect of buildings generates an important process of urban regeneration and the possibility of producing a new local economy (Della Torre, 2010). Conservation creates an interesting and unique environment, a place that gives physical expression to local identity, history, heritage and culture. The old building combined with the new function preserves the visual perception and the historical memory of the urban and landscape environment creating new economic dynamics and new scenarios of connection between the different countries (Yelenik, 2009). The roads' link is no longer only tangible, but imperceptible as our conservative project would create a connection between today's human reality and the history that has preceded it (UNESCO, 2003). Historic buildings are a tool to generate a sense of importance and identification for city residents. Conserving the building heritage must be conceived as a key tool to strengthen the unique nature of the city and attract tourists. Conservation must be an action that contributes to the development of activities related to culture, entertaining activities and leisure. A new use contributes to the creation of a widespread economic tourism (ICOMOS, 1999).

The identification of new methods of use for architectural and urban cultural heritage suggests the exercise of active protection, in a dynamic conservation, defined through projects of reuse and adaptation, and of valorisation also for cultural touristic purposes.

'To preserve rather than restore' (Bellini, 1994).

\section{REFERENCES}

Anas, (2016). "Case Cantoniere" in http://stradeanas.it/it.

Bellini, A. (1994). "Teorie del restauro e conservazione architettonica", in A. Bellini, Tecniche della conservazione. Milano: Franco Angeli. 
Boito, C. (1880). Carta di Atene in La conservation des monuments d'art et d'histoire - Conclusions de la conference d'Athenes, Paris,Institut de Coopération Intellectuelle, 1933.

Case Cantoniere, (2016). "Viaggiare, fermarsi, riscoprire. Manuale di progettazione" in http://www.casecantoniere.it/.

Della Torre, S. (2010). "Conservazione programmata: i risvolti economici di un cambio di paradigma. Il capitale culturale". Studies on the Value of Cultural Heritage, pp. 47-55. Macerata: EUM Edizioni Università di Macerata.

Gazzetta Ufficiale della Repubblica Italiana, (2016) - Serie Speciale - n. 81 del 15/07/2016.

Grandtour, (2016). "Il viaggio in Toscana dei viaggiatori Inglesi e Francesi dalla fine del XVII secolo agli inizi del XIX secolo" in http://grandtour.bncf.firenze.sbn.it/?set_language=en $\& \mathrm{cl}=\mathrm{en}$

Guidelines for the slow tourism, (2009). "Valorizzazione $e$ promozione di itinerari turistici "slow" tra l'Italia e la Slovenia", in Bando pubblico per la presentazione di progetti strategici n.01/2009

https://www.slow-tourism.net/contentsite/docs/Guidelines

ICOMOS, (1979). "The Burra Charter". Adopted by The Australia ICOMOS Charter for Places of Cultural Significance, 2013.

ICOMOS, (1999). International Cultural Tourism Charter, Managing Tourism at Places of Heritage Significance, Adopted by ICOMOS at the $12^{\text {th }}$ General Assembly in Mexico, October 1999.

ICOMOS, (2003). "Recommendations for the analysis, conservation and structural restoration of architectural heritage", in http://lecceworkshop.unile.it/Downloads/Recommendations

Yelenik, A. (2009). "Culture as a Tool for Urban Regeneration", The Jerusalem Institute for Israel Studies in https://en.jerusaleminstitute.org.il/.upload/publicatio ns/culture $\% 20$ and $\% 20$ urban\%20regeneration.pdf

Marcarini, A. (2005). "Il sentiero del viandante.Lungo la sponda orientale del lago di Como". Lyasis ed. ISBN-10 8886711557

Terre Lariane (2016). “Consorzio vini IGT" in http://www.terrelarianeigt.it/le-cantine/

UNESCO, (2003). "The value of the intangible Cultural heritage", Yamato Declaration 2004.

\section{Resume}

Francesca Andrulli was born in Italy. She is a tutor of the Architectural Restoration course at Politecnico di Milano, and she is a BIM construction engineer specialized in energy efficiency, mechanical design on both new and historic buildings. 
Chiara Bonaiti was born in Italy. She is a Tutor of Restoration class at the School of Building Architecture and Engineering at Polytechnic of Milan in Lecco. She is an Engineer specialized in energy efficiency and building renovation. She's a member of Association of Engineers in Lecco.

Alessia Silvetti is an adjunct professor of Conservation Studio at the international Master Architectural Engineering Polytechnic of Milan in Lecco, and adjunct professor of Restoration Studio at the School of Building Architecture and Engineering, Polytechnic of Milan in Lecco. She has been Tutor (2009-2016) of Restoration + studio classes at the School of Building Architecture and Engineering, and Tutor (2012-2016) of Conservation + studio classes at the international Master Architectural Engineering and Polytechnic of Milan in Lecco. She's received "Tangram of Architecture 2004" in an Italian National Competition. She's interested in intervention of conservation and her focus on the historical buildings and visual quality assessment in landscape architecture. She's a member of National Bioarchitecture Institute section of Lecco. 